\title{
The Bio-psycho-social Model and Beyond: Its Limitations and the Need for a New Model. A response to Eid's Editorial, "The Bio-Psycho-Social Model: How Accurate and Valid is it?"
}

Giovanni del Puente ${ }^{1}$ and Nicola Luigi Bragazzi ${ }^{2 *}$

${ }^{1}$ Psychiatry Department, DINOG, Department of Neuroscience, Ophthalmology and Genetics, University of Genoa, 16100 Genoa, Italy

${ }^{2}$ School of Public Health, Department of Health Sciences (DISSAL), University of Genoa, Via Pastore 1, 16132 Genoa, Italy

There is definitely an urgent need for a new health/disease model in psychiatry and, generally speaking, in internal medicine and in public health, as pointed out by Eid in his editorial [1]. The bio-psycho-social model developed by Engel [2] cannot capture the multidimensionality of the disease, which is indeed a dynamical [3] and complex phenomenon, characterized by "wholism, diversity, robustness and flexibility (as) hallmarks" [4]. We agree that biological, psychological and social levels are not separate at all : not only in the well-known sense that biological and social treatments have biological effects but also in the sense that biological and genetic potentials have a social impact, as shown by Damasio [5-7].

While many scholars have emphasized some missing dimensions in the classical bio-psycho-social model [8-10] or underpinned phenomena that fail and resist to be explained by that model [11-14], the model proposed by Eid [1] ("the somato-psycho-social model") can indeed overcome these limitations and pave the way for further research in the field.

\section{References}

1. Eid M (2012) The Bio-Psycho-Social Model: How accurate and valid is it? J Psychol Psychother 2: e103.

2. Engel GL (1977) The need for a new medical model: a challenge for biomedicine. Science 196: 129-136.

3. Bircher J (2005) Towards a dynamic definition of health and disease. Med Health Care Philos 8: 335-341.
4. Topolski S (2009) Understanding health from a complex systems perspective. J Eval Clin Pract 15: 749-754.

5. Anderson SW, Damasio H, Damasio AR (2005) A neural basis for collecting behaviour in humans. Brain 128: 201-212.

6. Immordino-Yang MH, McColl A, Damasio H, Damasio A (2009) Neura correlates of admiration and compassion. Proc Natl Acad Sci U S A 106: 8021 8026.

7. Damasio AR (1994) Descartes' error: Emotion, Reason, and the Human Brain. Quill, 312.

8. Lewy AJ, Emens JS, Songer JB, Sims N, Laurie AL, et al. (2009) Winte Depression: Integrating mood, circadian rhythms, and the sleep/wake and light/ dark cycles into a bio-psycho-social-environmental model. Sleep Med Clin 4 : 285-299.

9. Deshmukh VD (2008) The multistream self: biophysical, mental, social, and existential. ScientificWorldJournal 8: 331-341.

10. Leukefeld CG, Leukefeld S (1999) Primary socialization theory and a bio/ psycho/social/spiritual practice model for substance use. Subst Use Misuse 34: 983-991.

11. Johansson BH (2002) A bio-psycho-social model doesn't explain whiplash injury. Lakartidningen 99: 313-314.

12. Thayer JF, Brosschot JF (2005) Psychosomatics and psychopathology: looking up and down from the brain. Psychoneuroendocrinology 10: 1050-1058

13. Epstein RM, Borrell-Carrio F (2005) The biopsychosocial model: exploring six impossible things. Families, Systems \& Health 23: 426-431

14. McLaren N (1998) A critical review of the biopsychosocial model. Aust N Z J Psychiatry 32: 86-92.
*Corresponding author: Nicola Luigi Bragazzi, School of Public Health, Department of Health Sciences (DISSAL), University of Genoa, Via Pastore 1, 16132 Genoa, Italy, Tel: +39 0103538508; Fax: +39 0103538541; E-mail: robertobragazzi@gmail.com

Received September 01, 2012; Published October 20, 2012

Citation: Puente GD, Bragazzi NL (2012) The Bio-psycho-social Model and Beyond: Its Limitations and the Need for a New Model. A Response to Eid's Editorial, "The Bio-Psycho-Social Model: How Accurate and Valid is it?" 1:399. doi:10.4172/scientificreports.399

Copyright: ( 2012 Puente GD, et al. This is an open-access article distributed under the terms of the Creative Commons Attribution License, which permits unrestricted use, distribution, and reproduction in any medium, provided the original author and source are credited. 